\title{
The Role of Ceftazidime as a Photosensitizer in Human Erythrocytes through Oxidative Stress Mechanism
}

\author{
${\text { Mashuri }{ }^{1} \text {, Mustofa Ruhullah }}^{2}$, Bayu Diertama Putera², Vicky Pramudinta Mega², \\ Fadillah Alma Putra ${ }^{2}$, Eko Suhartono ${ }^{3, *}$ \\ ${ }^{1}$ Department of Radiology, Faculty of Medicine, Lambung Mangkurat University, Veteran Street No. 128, Banjarmasin 70232, South Kalimantan, \\ Indonesia \\ ${ }^{2}$ Faculty of Medicine, Lambung Mangkurat University, Veteran Street No. 128, Banjarmasin 70232, South Kalimantan, Indonesia \\ ${ }^{3}$ Department of Medical Chemistry/Biochemistry, Faculty of Medicine, Lambung Mangkurat University, Ahmad Yani Street Km. 36, Banjarbaru 70712, \\ South Kalimantan, Indonesia \\ *Corresponding author. E-mail: esuhartono@unlam.ac.id
}

Received date: Aug 15, 2017; Revised: Oct 25, 2017; Accepted: Nov 1, 2017

\section{Abstract}

B ACKGROUND: Ceftazidime was known to cause photosensitization reactions. However, how it plays the role remained unclear. In our study, we aim to investigate the photosensitization effect of ceftazidime in erythrocytes via oxidative stress.

METHODS: Samples were divided into six different groups: negative control group, positive control group and four experimental groups with $10 \%, 20 \%, 30 \%$, and $40 \%$ ceftazidime, respectively. The positive control and experimental groups were exposed to ultraviolet (UV)-light for 2 hours. Superoxide radical, malondialdehyde (MDA), carbonyl compounds (CC) and methemoglobin (Met-Hb) levels were then measured.

RESULTS: The results showed a significant increased of superoxide radical, MDA, $\mathrm{CC}$ and Met- $\mathrm{Hb}$ levels in all experimental groups compared to both negative or positive control groups $(p<0.05)$.

CONCLUSION: In conclusion, our study confirmed the role of ceftazidime as a photosensitizer in erythrocytes via the oxidative stress mechanisms.

KEYWORDS: ceftazidime, oxidative stress, photosensitizer, photosensitization.

Indones Biomed J. 2018; 10(2): 128-32

\section{Introduction}

Cell membranes consisted of large amounts of lipids and proteins which were susceptible to reactive oxygen species (ROS) attack, i.e., oxidative stress. This can cause membrane damage and results in cell death. Oxidative stress can occur through many mechanisms, the most common is by photosensitization.(1) Photosensitization needs both photosensitisizer and solar radiation. A photosensitizer absorbs energy from lights and transforms it into chemical energy. It also promotes further reaction to transfers the energy under favorable conditions and resulted in unreactive substrates.(2) While solar radiation is the radiant energy emitted by the sun, include ultraviolet (UV)-A, UV-B, and UV-visible (UV-vis).(3-4)

A photosensitizer could be cellular substances (such as flavins and porphyrins) from foods, cosmetics, plants or plants extract, industrial chemicals (such as dye, coal, tar and chlorinated hydrocarbons) and drugs.(4-5) Despitefully their benefit, drugs, especially antimicrobials and their derivatives induce the photosensitization because most of them (such as quinolones and tetracyclines) contain cyclic and tricyclic hydrocarbons, which have double-bond isoprene or naphthyridine nucleus.(5-7) This interest us to observe how the other antimicrobial agent, particularly ceftazidime do its role as a photosensitisizer in erythrocytes through oxidative stress mechanism. 
Ceftazidime is the third generation of cephalosporin. This antibiotic was widely used to treat gram-negative bacteria infection, such as Escherichia coli, Citrobacter diversus, Citrobacter freundii, Enterobacter aerogenes, Enterobacter agglomerans, Klebsiella pneumoniae, Proteus spp., Serratia marcescens, Salmonella spp., Shigella spp. and Pseudomonas aeruginosa.(8-9) Ceftazidime exerts its activity by binding to penicillin-binding proteins (PBPs) within the bacteria's cell wall, primarily PBP-3, interfering with cell division thus leading to cell death. (10) Ceftazidime is also known to have a photosensitizer property (7), but the mechanisms were remain unclear. Until recently, there have been no investigations of ceftazidime as a photosensitizer in erythrocytes through oxidative stress mechanism. Therefore, our study was aimed to investigate aforementioned. Superoxide radical level will be measured as it was expressed in photosensitivity reaction. Malondialdehyde (MDA), and carbonyl compound (CC) will be measured to assess the membrane damage due to ROS. Meanwhile, the oxidative damage in erythrocytes will be observed by Met-Hb measurement.

\section{Methods}

\section{Sample Preparation and Experimental Models}

Unit of $250 \mathrm{~mL}$ packed red blood cells was obtained from the Indonesian Red Cross in Martapura, Banjar, South Kalimantan, Indonesia. Samples were divided into six groups. Four replication performed for each group. Group 1 served as a negative control which consists of $1 \mathrm{~mL}$ of erythrocytes and buffer phosphate with $\mathrm{pH}$ 6.8. Group 2 served as a positive control which consists of $1 \mathrm{~mL}$ of erythrocytes and buffer phosphate with $\mathrm{pH} 6.8$ and exposed to UV-light for 2 hour. Group 3, 4, 5 and 6 served as experimental groups which consists of $1 \mathrm{~mL}$ of erythrocytes, buffer phosphate with $\mathrm{pH} 6.8$ and ceftazidime with concentration $10 \%, 20 \%, 30 \%$, and $40 \%$, respectively. The experimental groups were exposed to UV-light for 2 hours. After treatment, the superoxide radical, MDA, CC and Meth- $\mathrm{Hb}$ levels were measured. This experiment complied with the guidelines of the Institute of Laboratory Animal Resources, Commission on Life Sciences, National Research Council and were approved by the Ethical Committee of the Faculty of Medicine, University of Lambung Mangkurat, Banjarbaru, South Kalimantan, Indonesia (Ethical approval number: 403/KEPK-FK UNLAM/EC/VI/2017).

\section{Superoxide Radical Level Analysis}

The superoxide radical level was determined according to the modified method of Misra and Fridovich.(11) Samples were added to $0.800 \mathrm{~mL}$ of carbonate buffer (100 $\mathrm{mM}, \mathrm{pH} 10.2$ ) and $100 \mu \mathrm{L}$ of adrenaline $3 \mathrm{mM}$, producing adrenochrome. The absorbance from adenochrome was measured at $480 \mathrm{~nm}$ represented superoxide radical level.

\section{MDA Level Analysis}

MDA level was determined according to the method of Buege and Aust, based on the reaction with thiobarbituric acid reactive substances (TBARS) in $10 \%$ of trichloracetic acid and $0.67 \%$ of thiobarbituric acid at $100^{\circ} \mathrm{C}$ for 15 minutes.(12) The mixture was cooled on ice for 5 minutes and $1.5 \mathrm{~mL}$ of n-butyl-liquor were joined. The mixture then incubated for 40 seconds and centrifuged at $1000 \mathrm{rpm}$ for 15 minutes. The supernatant absorbance was read at $500 \mathrm{~nm}$. The results were calculated using an index of absorption for MDA of $1.56 \times 10^{5} \mathrm{~mol} / \mathrm{cm}$. The MDA concentration expressed as $\mu$ mol MDA. Commercially MDA was used as standard solution.

\section{Carbonyl Compound Level Analysis}

The total CC level was determined by colorimetric method. Samples were pipetted into $1.5 \mathrm{~mL}$ centrifuge tube. Then, $0.5 \mathrm{~mL}$ of $10 \mathrm{mM}$ 2,4-dinitrophenylhydrazine (DNPH) in 2 $\mathrm{M} \mathrm{HCl}$ was added and being put at room temperature for 1 hour and vortexing every 10-15 minutes. A $0.5 \mathrm{~mL}$ of $20 \%$ trichloroacetic acid was added, followed by centrifugation. The supernatant was discarded and the pellets were washed 3 times with $1 \mathrm{~mL}$ ethanol-ethyl acetate $(1: 1)$ to remove the free reagent. Furthermore, from the washing result was obtained the protein precipitate dissolved in $0.6 \mathrm{~mL}$ guanidine solution. The precipitate protein was measured at the $390 \mathrm{~nm}$. The result of the absorbance equal to CC level in the sample solution.(13-14)

\section{Met-Hb Level Analysis}

Met-Hb level was estimated according to cyanmethemoglobin method as described by Evelyn and Malloy. To calculate the Met-Hb level in erythrocytes, the absorbance of erythrocyte lysates at $630 \mathrm{~nm}(\mathrm{~S} 1)$ was initially measured. Potassium cyanide $(\mathrm{KCN})$ was then added and the absorbance of the solution at $630 \mathrm{~nm}$ (S2) was measured. Potassium ferricyanide $\left(\mathrm{K}_{3} \mathrm{Fe}(\mathrm{CN})_{6}\right)$ was added to converted hemoglobin into Met-Hb. The absorbance at $630 \mathrm{~nm}$ (T1) was measured before (T1) and after (T2) 
the $\mathrm{KCN}$ was added. Met-Hb content was expressed as a percent calculated on the basis of the equation [100(S1-S2)] / [10(T1-T2)].(15-16)

\section{Statistical Analysis}

Results are expressed as mean \pm standard error (SE). The effects of treatments were compared using One way analysis of variance (ANOVA) followed by Tukey HSD test, which is done with SPSS version 16.0 (SPSS Inc., Chicago, IL, USA) version 16.0. The level of significance was set at $p<0.05$.

\section{Results}

One way ANOVA followed by Tukey HSD test with significance level of $p<0.05$ was done to compare the difference of superoxide radical levels in each group. Figure 1 showed the superoxide radical levels in human erithrocytes after UVlight exposure, with and without ceftazidime. Superoxide radical levels in positive control and experimental groups (group 2,3,4,5 and 6) were significantly different compared to the negative control (group 1) $(p<0.001)$. The level of superoxide radical in positive control and experimental groups were significantly increased. The superoxide radical levels in the experiment groups with ceftazidime (group $3,4,5$ and 6) were also significantly higher $(p<0.001)$ compared to positive control (group 2). The effect was dosedependent.

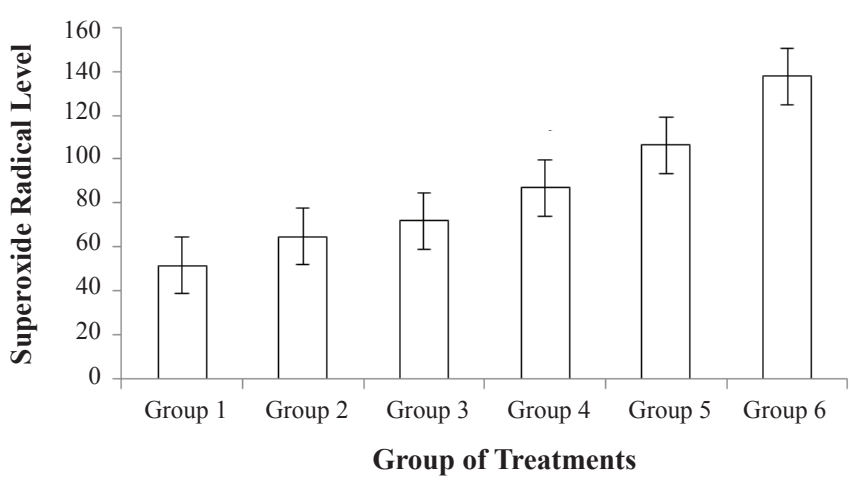

Figure 1. Superoxide radical levels in human erithrocytes after UV-light exposure, with and without ceftazidime.

The same test as before was done to compare the MDA level. In figure 2 we could see the effect of both UVlight and ceftazidime on MDA level in erythrocytes. There

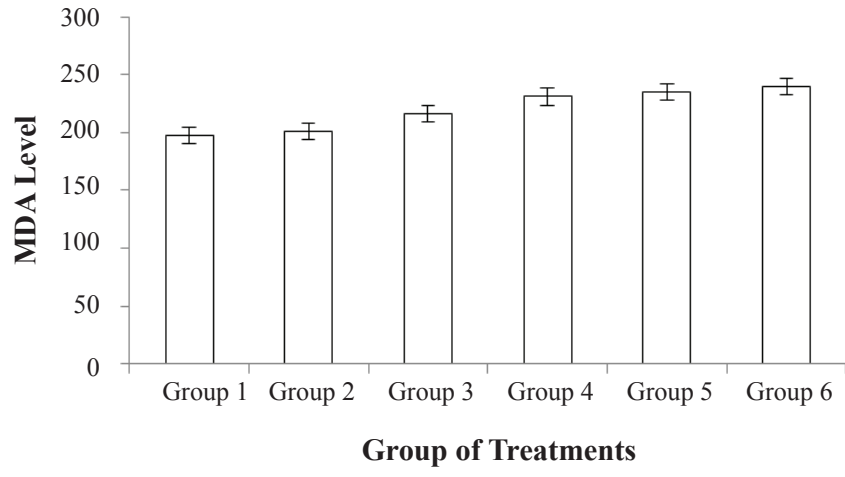

Figure 2. MDA levels in human erithrocytes after UV-light exposure, with and without ceftazidime.

were a significant increase of MDA level in positive control and experimental groups (group 2,3,4,5 and 6) compared to negative control group (group 1) ( $p=0.001)$. MDA level in experimental groups (group 3,4,5 and 6) were significantly higher compared to positive control group (group 2) $(p=0.002)$. The effect was displayed in a dose-dependent manner.

Figure 3 showed the effect of both UV-light and ceftazidime on $\mathrm{CC}$ level in erythrocytes. Also with one way ANOVA which followed by Tukey HSD test, it was found that $\mathrm{CC}$ level in the positive control and experimental groups (group 2,3,4,5 and 6) were significantly increased compared to the negative control group (group 1) $(p<0.001)$. With $p=0.035$, the treated group (group 3,4,5 and 6) were also different compared to the positive control group (group 2). The effect was displayed in a dose-dependent manner.

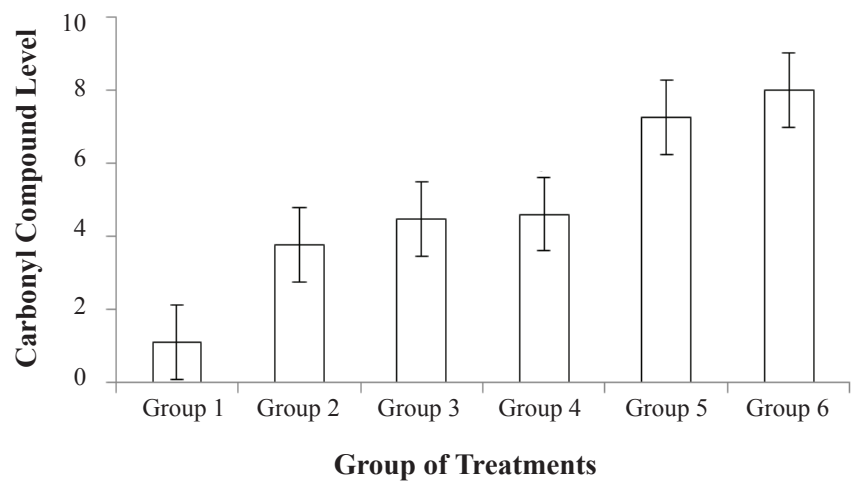

Figure 3. CC levels in human erithrocytes after UV-light exposure, with and without ceftazidime.

Meanwhile, the effect of UV-light and UV-light added with ceftazidime in Met-Hb levels were showed in Figure 4. Compared to negative control (group 1), Met-Hb level 


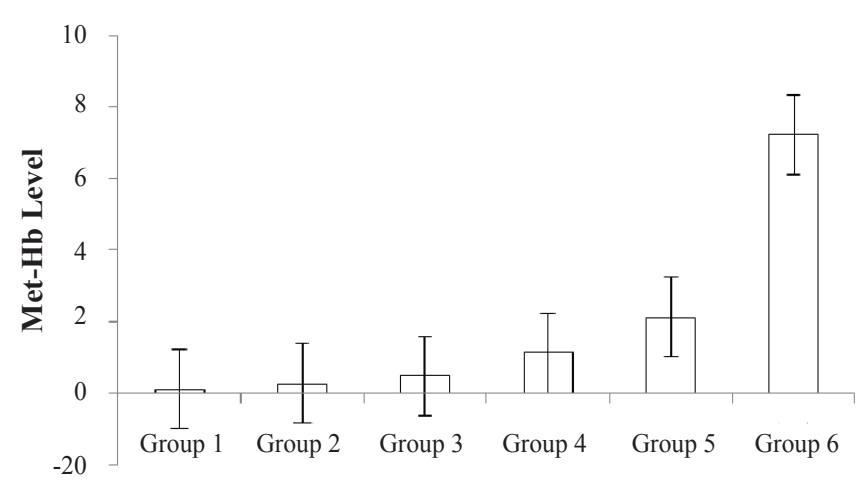

Group of Treatments

Figure 4. Met-Hb levels in human erithrocytes after UV-light exposure, with and without ceftazidime.

in positive control and experimental groups (group 2,3,4,5 and 6$)$ were significantly higher $(p<0.001)$. And compared to positive control (group 2), the experimental groups (group 3,4,5 and 6) also shown to have significantly higher Met$\mathrm{Hb}$ level $(p<0.001)$. The effect was dose-dependent manner.

\section{Discussion}

Ceftazidime was known to cause photosensitization reactions. However, how it plays the role remained unclear. In our study, we aim to investigate the photosensitization effect of ceftazidime in erythrocytes via oxidative stress. Our results showed that ceftazidime increased the level of superoxide radical, MDA and CC with UV-light exposure. This suggested that ceftazidime act as a photosensitizer in erythrocytes. Ceftazidime absorbs UV radiation and resulted in excited species. This step is known as a singlet state. (4) These excited photosensitizers then promote a further reaction to damage biomolecules via four pathways, which are (1) the excited photosenstizer could transfer the energy to oxygen results in the formation of singlet oxygen which might promote a further reaction to oxidizied membran lipid or protein results in the formation of MDA and other CC; (2) electron or hydrogen transfer from another compound to the photosensitizer can trigger the formation of ROS that can directly cause damage to other biomolecules such as lipids and proteins. It can also trigger the formation of $\mathrm{CC}$ and MDA as an oxidation products of ROS; (3) the excited photosensitizer could make a direct covalent binding to biomolecules, thus also inducing cell damage; and (4) the photosensitizer could undergo a decomposition, such that the resulting photoproducts can act either as toxins or as new photosensitizers.(17)
To prove the phototoxic effect of ceftazidime on erythrocytes, we also measured Met-Hb levels. Met-Hb has been recognized to be the parameters of erythrocyte damage due to oxidative reactions. Some studies found the increasing of Met- $\mathrm{Hb}$ in several pathological conditions related to oxidative stress.(18-19) The increasing Met- $\mathrm{Hb}$ levels after ceftazidime and UV-light exposures indicated that ceftazidime act as a photosensitizer in erythrocytes. However, to best of our knowledge, some studies and reviews have clearly stated that antibiotics such as ceftazidime may act as photosensitizers and cause photosensitization reactions. But there have been no similar research which has investigated the effects of ceftazidime photosensitization on erythrocytes via this mechanism.

\section{Conclusion}

In conclusion, the results of this study confirmed the role of ceftazidime as a photosensitizer in erythrocytes via the oxidative stress mechanisms.

\section{References}

1. Riske KA, Sudbrack TP, Archilla NL, Uchoa AF, Schroder AP, Marques CM, et al. Giant vesicles under oxidative stress induced by a membrane-anchored photosensitizer. Biophys J. 2009; 97: 136270.

2. Pei D, Luan J. Development of visible light-responsive sensitized photocatalysts. Int J Photoenergy. 2012; 2012: 1-13.

3. Hiraku Y, Ito K, Hirakawa K, Kawanishi S. Photosensitized DNA damage and its protection via a novel mechanism. Photochem Photobiol. 2007; 83: 205-12.

4. Quintero B, Miranda MA. Mechanisms of photosensitization induced by drugs: a general survey. Ars Pharmaceutica. 2000; 41: 27-46.

5. Dubakiene R, Kupriene M. Scientific problems of photosensitivity. Medicina. 2006; 42: 619-24.

6. Zuba EB, Koronowska S, Osmola-Mankowska A, Jenerowicz D. Drug-induced photosensitivity. Acta Dermatovenerol Croat. 2016; 24: 55-64.

7. Gill L, Lim HW. Drug-induced photosensitivity. In: Hall JC, Hall BJ, editor. Cutaneous Drug Eruptions: Diagnosis, Histopathology and Therapy. London: Springer-Verlag London; 2015. p107-21.

8. Moreno AH, Salgado HRN. Stability study and degradation kinetics of ceftazidime in pharmaceutical preparations. Adv Anal Chem. 2012; 2: 1-5.

9. Rule R, Villagra S, Barrena P, Lacchini R, Reynaldi FJ. Pharmacokinetics of ceftazidime administered to lactating and nonlactating goats. Tydskr S Afr Vet Ver. 2011; 82: 219-23.

10. Barber KE, Ortwine JK, Akins RL. Ceftazidime/avibactam: who says you can't teach an old drug new tricks?. J Pharm Pharm Sci. 2016; 19: 448-64. 
11. Suhartono E, Iskandar, Hamidah S, Arifin YF. Phytochemical constituents analysis and neuroprotective effect of leaves of gemor (nothaphoebe coriacea) on cadmium-induced neurotoxicity in rats: an in-vitro study. International Journal of Toxicological and Pharmacological Research 2015; 7: 297-302.

12. Suhartono E, Triawanti, Yunanto A, Firdaus RT, Iskandar. Chronic cadmium hepatooxidative in rats: treatment with haruan fish (Channa striata) extract. Approaches. In: International Conference on Environmental Science and Development, January 19-20, 2013, Dubai, United Arab Emirates. Hongkong: Asia-Pacific Chemical, Biological \& Environmental Engineering Society; 2013.

13. Yunanto A, Iskandar, Suhartono E. In-vitro effects of some antibiotic drugs on saliva thiocyanate and oxidation protein products levels on newborn at risk of sepsis. IJPCR. 2016; 8: 86-9.

14. Suhartono E, Bahriansyah M, Triawanti. The inhibition effect of kelakai (Stenochlaena palustris) extract on cadmium-induced glycation and fructation in-vitro. IJPCR. 2016; 8: 248-53.
15. Srivastava S, Alhomida AS, Siddiq NJ, Puri SK, Pandey VC. Methemoglobin reductase activity and in vitro sensitivity towards oxidant induced methemoglobinemia in Swiss mice and beagle dogs erythrocytes. Mol Cell Biochem. 2002; 232: 81-5.

16. Zama I, Yakubu A, Okwesili AN, Ishaku EY, Erhabor O, Mainasara AS, et al. Prevalence of malaria parasitaemia and methaemoglobin levels among blood donors in Sokoto, Nigeria. Internal Medicine Inside. 2013; 1-4.

17. Zaheer MR, Gupta A, Iqbal J, Zia Q, Ahmad A, Roohi, et al. Molecular mechanisms of drug photodegradation and photosensitization. Current Pharm Design. 2016; 22: 1-15.

18. Hermann PB, Pianovski MA, Henneberg R, Nascimento AJ, Leonart MS. Erythrocyte oxidative stress markers in children with sickle cell disease. J Pediatr. 2016; 92: 394-9.

19. Kanias T, Acker JP. Bioprservation of red blood cells - the struggle with hemoglobin oxidation. FEBS Journal. 2010; 277: 343-56. 